\title{
The impact of opioid medications on subsequent fractures in discharged emergency department patients with peripheral vertigo
}

\author{
Keerat Grewal, MD*; Peter C. Austin, PhD ${ }^{\dagger \oplus \| ;}$; Moira K. Kapral, MD, MSc ${ }^{\ddagger \mp \|}$; Hong Lu, MSc, PhD; \\ Clare L. Atzema, MD, MSc ${ }^{*}$
}

\section{ABSTRACT}

Background: Vertigo is common in the emergency department (ED). Most aetiologies are peripheral and do not require hospitalization, but many patients still fear falling. Some patients may be taking opioid analgesic medications (for other reasons); the risk of falls leading to fractures among patients with vertigo could be potentiated by the simultaneous use of opioids.

Objectives: To examine the risk of fractures in discharged ED patients with peripheral vertigo who were being prescribed opioids during the same time period.

Methods: Linked administrative databases from Ontario were used to compare discharged ED patients aged $\geq 65$ with peripheral vertigo to patients with urinary tract infection (UTI) from 2006 to 2011. We used Cox regression analysis with an interaction term to estimate the modifying effect of an opioid prescription on the hazard of fracture within 90 days.

Results: There were 13,012 patients with a peripheral vertigo syndrome and 76,885 with a UTI. Thirteen percent of the vertigo cohort and $25 \%$ of the UTI cohort had access to a filled opioid prescription. Compared to vertigo patients who did not fill an opioid prescription, the adjusted hazard of fracture among vertigo patients who did fill a prescription was 3.59 (95\% Cl 1.97-6.13). Among UTI patients who filled an opioid prescription the hazard ratio was 1.68 (95\% Cl 1.43-1.97) compared to UTI patients who did not.

Conclusions: Patients discharged from the ED with peripheral vertigo who were also being prescribed opioids had a higher hazard of subsequent fracture compared to those who were not, and the effect was much greater than among UTI patients. These results suggest that in the acutely vertiginous older patient, opioid analgesic medications should be modified, where possible.

\section{RÉSUMÉ}

Contexte: Les vertiges sont une cause fréquente de consultation au service des urgences (SU). La plupart sont d'origine périphérique et ne nécessitent pas d'hospitalisation, mais bon nombre de patients craignent toujours de faire des chutes. Certains malades peuvent prendre des analgésiques opioïdes (pour d'autres raisons), et le risque de chute causant des fractures chez les patients qui souffrent de vertiges pourrait être aggravé par la prise concomitante d'opioïdes.

Objectifs : L'étude visait à examiner le risque de fracture chez les patients ayant obtenu leur congé du SU mais éprouvant des vertiges d'origine périphérique, à qui I'on avait prescrit des opioïdes durant la même période.

Méthode: Nous avons établi des liens entre des bases de données administratives en Ontario afin de comparer des patients âgés de 65 ans et plus, atteints de vertiges d'origine périphérique mais ayant obtenu leur congé du SU, avec des patients souffrant d'une infection urinaire (IU), pour la période de 2006 à 2011. Une analyse de régression de Cox avec paramètre d'interaction a permis d'estimer l'effet modificateur des prescriptions d'opioïdes sur le risque de fracture au cours des 90 jours suivants.

Résultats: L'étude comptait 13012 patients éprouvant des vertiges d'origine périphérique et 76885 patients souffrant d'une IU. Treize pour cent de ceux qui se trouvaient dans la cohorte des malaises vertigineux et $25 \%$ de ceux qui se trouvaient dans la cohorte des IU ont fait exécuter une ordonnance d'opioïdes. Le risque rajusté de fracture chez les patients qui avaient des vertiges et qui avaient fait exécuter une ordonnance d'opioïdes comparativement à ceux qui ne l'avaient pas fait était de 3,59 (IC à $95 \%$ : 1,97-6,13). Quant aux patients souffrant d'une IU, le rapport des risques instantanés était de 1,68 (IC à $95 \%$ : 1,43-1,97) entre ceux qui avaient fait exécuter une ordonnance d'opioïdes et ceux qui ne l'avaient pas fait.

Conclusions: Le risque de fracture consécutif à la prise d'opioïdes était plus élevé chez les patients éprouvant des vertiges d'origine périphérique mais ayant obtenu leur congé du SU, à qui I'on avait prescrit des opioïdes que chez ceux à qui I'on n'en avait pas prescrit, et l'effet était beaucoup plus grand que chez les patients souffrant d'une IU. Les résultats

From the *Department of Medicine, Division of Emergency Medicine, University of Toronto, Toronto, ON; †Sunnybrook Health Sciences Centre, University of Toronto Faculty of Medicine, Toronto, ON; $\neq$ University Health Network, University of Toronto, Toronto, ON; ףInstitute of Health Policy, Management, and Evaluation, University of Toronto, Toronto, ON; and IInstitute for Clinical Evaluative Sciences, Toronto, ON.

Correspondence to: Dr. Keerat Grewal, Institute for Clinical Evaluative Sciences, 2075 Bayview Avenue, Room G157, Toronto ON M4N 3M5; Email: keerat.grewal@mail.utoronto.ca 
donnent à penser qu'il faudrait modifier, dans la mesure du possible, les opioïdes chez les patients âgés qui éprouvent des vertiges importants.
Keywords: peripheral vertigo, opioids, bone, emergency department

\section{INTRODUCTION}

Dizziness is a common reason for presentation to an emergency department (ED). ${ }^{1}$ Vertigo, or the sensation of movement relative to the surroundings, is usually classified as a subcategory of dizziness. ${ }^{2,3}$ Vertigo has both peripheral and central causes, with most vertigo being peripheral (inner ear) in aetiology.,

While the exclusion of central causes of vertigo (such as a cerebellar or brainstem stroke) is essential in the emergency assessment of the vertiginous ED patient, ${ }^{3-5}$ peripheral causes of vertigo may be nonetheless debilitating. In a review of the physical and psychological consequences of vertigo, ${ }^{6}$ a range of symptoms were described, including involuntary eye movements, anxiety, disorientation, and fear of falling. However, our recent work $^{7}$ found no increased risk of injury among these patients when compared to matched controls. Many medications, however, have a side-effect profile that includes dizziness, and it is possible that the combination of this side effect and a peripheral vertiginous syndrome amplifies the risk of falls. Opioid use is high in North America $^{8,9}$ and has been associated with an increased risk of falls and fractures among the elderly. ${ }^{10}$ The risk of falls leading to fractures in the vertiginous patient could be amplified in patients who use opioid analgesic medications. To the best of our knowledge, however, there is currently no evidence to justify this concern.

The large majority of patients with peripheral vertigo are discharged home from the ED. ${ }^{7}$ The purpose of this study was to determine whether patients who were discharged from the ED with a peripheral vertigo syndrome were at increased risk of subsequent injury resulting in bone fractures if they also had access to a filled prescription for an opioid analgesic medication.

\section{METHODS}

\section{Study design}

This was a retrospective cohort study using linked administrative health databases from the Canadian province of Ontario. Research ethics board approval was obtained from the Sunnybrook Health Sciences Centre.

\section{Data sources and study population}

Patients were identified from the Canadian Institute for Health Information National Ambulatory Care Reporting System (CIHI-NACRS), an administrative database that contains anonymised, abstracted data on all ED patient visits in the province of Ontario. Patients in the CIHI-NACRS between the ages of 65 and 105 who had an $\mathrm{ED}$ visit with a primary diagnosis of peripheral vertigo (International Classification of Disease, 10th edition [ICD-10] codes H81.1, H81.2, or H81.3) between 1 April 2006 and 31 March 2011 were eligible for inclusion. We previously validated the ICD-10 codes for peripheral vertigo in the CIHI-NACRS by examining ED charts from several sites: positive predictive value of $97.7 \%$ (95\% confidence interval [C] $95.0-99.1 \%) .{ }^{11}$

The cohort was limited to patients aged 65 years and older because comprehensive medication data were only available in the Ontario Drug Benefit database for this cohort. Only the index ED visit (the initial visit within the study period) was included. Patients were excluded if they were admitted to the hospital from the ED, were from a long-term care facility/nursing home, died in the ED, or were seen in an ED that was not open 24 hours a day.

In order to provide context for the frequency of outcomes found in the vertigo cohort, a comparator cohort was selected. The comparator group had to meet the following criteria: commonly seen in the emergency setting; often discharged home from the ED; and an intermittent (not chronic) disease that is, in and of itself, not associated with poor outcomes. We selected patients with a primary ED diagnosis (i.e., first diagnosis written in the ED chart) of urinary tract infection (UTI) (ICD-10 codes N30.0, N34.1, or N39.0). The same exclusion criteria that were applied to the peripheral vertigo cohort were applied to the control UTI cohort.

To determine comorbidities, prescription medications, and outcomes, both the vertigo and UTI cohorts in the CIHI-NACRS were linked to other provincewide administrative databases using unique encoded identifiers. The Discharge Abstract Database contains data on all acute-care hospitalizations in Ontario, and the Ontario Health Insurance Plan contains billings for all physician visits and procedures in any setting. ${ }^{12}$ 


\begin{tabular}{|c|c|c|c|}
\hline Opioid component & $\begin{array}{l}\text { No. of patients* } \\
\qquad N=89,897\end{array}$ & $\begin{array}{l}\text { Vertigo patients (\%) } \\
\quad n=13,012\end{array}$ & $\begin{array}{c}\text { UTI patients (\%) } \\
\quad n=76,885\end{array}$ \\
\hline Any & $20,645(23.0)$ & $1,676(12.9)$ & $18,969(24.7)$ \\
\hline Butorphanol & $0(0.0)$ & $0(0.0)$ & $0(0.0)$ \\
\hline Codeine & 12,485 (13.9) & $1,117(8.6)$ & $11,368(14.8)$ \\
\hline Dextropropoxyphene & $0(0.0)$ & $0(0.0)$ & $0(0.0)$ \\
\hline Fentanyl & $1,540(1.7)$ & $60(0.5)$ & $1,480(1.9)$ \\
\hline Hydrocodone & $703(0.8)$ & $98(0.8)$ & $605(0.8)$ \\
\hline Hydromorphone & $2,394(2.7)$ & $94(0.7)$ & $2,300(3.0)$ \\
\hline Meperidine & $158(0.2)$ & $8(0.1)$ & $150(0.2)$ \\
\hline Morphine & $1,688(1.9)$ & $72(0.6)$ & $1,616(2.1)$ \\
\hline Oxycodone & $6,036(6.7)$ & 430 (3.3) & $5,606(7.3)$ \\
\hline Oxymorphone & $0(0.0)$ & $0(0.0)$ & $0(0.0)$ \\
\hline Pentazocine & $0(0.0)$ & $0(0.0)$ & $0(0.0)$ \\
\hline Propoxyphene & $0(0.0)$ & $0(0.0)$ & $0(0.0)$ \\
\hline
\end{tabular}

The Registered Persons Database contains validated mortality information for all Ontario residents (including out-of-hospital deaths), ${ }^{13}$ and the Home Care Database contains information on all home care visits by allied health care professionals. Ontario has universal health care coverage for medically necessary care, and, therefore, these databases contain the vast majority of health care utilization in the province.

The Ontario Drug Benefit database provides coverage for prescription medications for Ontarians aged 65 and older. This database contains the date a prescription was filled and the number of days' supply of medication dispensed, which can be used to calculate whether the patient filled a new prescription after ED discharge (i.e., a new opiate prescription) or had access to the medication via a previous prescription fill (e.g., a chronic opiate prescription), based on a supply that extended beyond the date of ED discharge-in other words, the opioid prescriptions were not necessarily from the ED visit for vertigo. We included all patients with vertigo or UTI who simultaneously had access to an opioid prescription for any reason, from any provider. We included non-injectable opioid analgesic medications that were available for prescription in Ontario during the study period (Table 1).

\section{Outcome measures}

The primary outcome measure was the occurrence of an ED visit or hospital admission for a fracture within 90 days of ED discharge.

\section{Data analysis}

Patient characteristics were compared using descriptive statistics. A cause-specific hazard model was used to estimate the effect of vertigo on the hazard of fracture, compared to that in UTI patients. A filled prescription of an opioid analgesic medication was included as a time-varying covariate, in which each patient's access to an opioid analgesic medication on each day of follow-up was determined using the date on which the most recent prescription was filled and the number of days for which medication was provided. Thus, the estimated hazard ratio for opioid use denotes the effect of access to a current opioid prescription on the hazard of a fracture. Patients were censored at the end of the study period (i.e., after 90 days of observation) if event-free. The model accounted for the competing risks of death and hospitalization for another reason. An interaction term between the cohort (vertigo vs. UTI) and opioid medication was incorporated into the model. This allowed the effect of opioid use to vary between the two cohorts. It allowed us to estimate the hazard of the outcome associated with 1) an opioid medication among the vertigo cohort (compared to no opioid in the same group), and 2) an opioid medication among the UTI cohort (compared to no opioid in that group). To estimate this hazard, the parameter estimates of individual groups (e.g., UTI no opioid, UTI with opioid, vertigo no opioid, vertigo with opioid) must be calculated using the parameter estimates for each model variable, instead of directly interpreting the parameter 
estimates in the model output (see Appendix, Table E1).

Additional covariates for inclusion in the model were determined via review of the published literature, focusing on variables that may be associated with the risk of injury. Where available, validated algorithms were used to identify the comorbidities in the linked administrative databases, including acute myocardial infarction, hypertension, congestive heart failure, and diabetes. ${ }^{14-18}$ Where validated algorithms were not available, the patient was considered to have a past medical history of the disease in question if they had one diagnosis in the Discharge Abstract Database (any of the 25 potential diagnoses), or two main diagnoses in the CIHI-NACRS, or two outpatient diagnoses in the Ontario Health Insurance Plan database, or one of each from the CIHI-NACRS and the Ontario Health Insurance Plan database, within the five years prior to the ED visit. This approach is consistent with several of the validated algorithms. ${ }^{17,18}$ The Johns Hopkins Adjusted Clinical Group (ACG) case-mix system is a measure of patient acuity/comorbidity. ${ }^{19}$ In an ambulatory cohort, its purpose is similar in principle to the use of the Charlson Comorbidity Index in studies of hospitalized patients. ${ }^{20}$ Diagnoses are assigned to one of 32 diagnostic clusters; patients with the largest number of high-risk clusters are generally sickest and require the most health care resources.

To ensure that the effect of the opioid was not confounded by other medications that also have the potential to cause dizziness and/or sedation (of which there are too many to add to our model), we performed a sensitivity analysis. We added a filled prescription for a benzodiazepine to the model to determine whether the association of opioid medication with the outcome was removed. All analyses were performed with SAS software (v. 9.3, SAS Institute, Cary, NC).

\section{RESULTS}

There were 13,012 qualifying patients with a primary diagnosis of peripheral vertigo and 76,885 with a UTI. The median age of the vertigo cohort was 75 (interquartile range [IQR] 70-80) years compared to 77 (IQR 72-83) in the UTI cohort (Table 2). Just over $60 \%$ of vertigo patients were female (61.6\%), compared to $68.5 \%$ of the UTI group. Patients in the UTI cohort had a higher proportion of comorbidities, hospitalizations, and home care use than those in the peripheral vertigo cohort.
Among the vertigo patients, $79(0.61 \%)$ sustained a fracture within 90 days of discharge from the ED, compared to $964(1.25 \%)$ among patients with a UTI (Table 3). A total of $13 \%$ of the vertigo patients had access to opioid analgesic medication after discharge, compared to $25 \%$ of the UTI patients.

The coefficients for the cause-specific hazard model are shown in the online appendix (Table 4). The interaction term between cohort (vertigo vs. UTI) and opioid medication prescription was significant $(p=0.01)$, indicating that the effect of opioids on the hazard of fracture differed between those with vertigo and those with a UTI. Compared to vertigo patients who did not fill an opioid analgesic prescription, the adjusted hazard of fracture among vertigo patients who filled an opioid analgesic medication prescription was 3.59 (95\% CI 1.97-6.13). Comparing UTI patients who filled an opioid analgesic medication prescription to those who did not, the adjusted hazard of fracture was 1.68 (95\% CI 1.43-1.97). Other variables that were associated with the outcome included older age; female sex; a history of heart failure, dementia, Parkinson's disease, and falls; a home care visit within the prior 3 months; and arriving at the ED via ambulance. In the sensitivity analysis that included filled benzodiazepine prescriptions in the model, the results were similar.

\section{DISCUSSION}

In this study, we found that patients who were discharged from the ED with a diagnosis of a peripheral vertigo syndrome had more than three times (a 259\% increase) the hazard of suffering a broken bone within the subsequent 90 days if they had a filled prescription for opioid analgesic medication, compared to patients with vertigo without such a prescription. In comparison, patients with a UTI who had been prescribed an opioid analgesic medication had a much smaller increase in risk of fracture (68\% increase). We observed that, when combined with vertiginous symptoms, the risk of a fracture is amplified beyond the risk associated with opioid medications alone. These results suggest that emergency physicians, as well as physicians involved in follow-up care, should review the medication list of patients they are discharging with a diagnosis of peripheral vertigo and adjust it to minimize opioid use whenever possible.

While the risk of a broken bone was much higher if the patient had access to opioid analgesic medications, 


\begin{tabular}{|c|c|c|c|}
\hline Characteristic & $\begin{array}{c}\text { Total } \\
(N=89,897)\end{array}$ & $\begin{array}{l}\text { Vertigo patients } \\
\quad(n=13,012)\end{array}$ & $\begin{array}{l}\text { UTI patients } \\
(n=76,885)\end{array}$ \\
\hline \multicolumn{4}{|l|}{ Demographics } \\
\hline \multicolumn{4}{|l|}{ Age } \\
\hline Mean \pm SD & $77.6 \pm 7.5$ & $75.6 \pm 6.6$ & $77.9 \pm 7.5$ \\
\hline Median (IQR) & $77(71-83)$ & $75(70-80)$ & $77(72-83)$ \\
\hline Female sex & $60,640(67.5 \%)$ & $8,011(61.6 \%)$ & $52,629(68.5 \%)$ \\
\hline \multicolumn{4}{|l|}{ Income quintile } \\
\hline 1 & $20,122(22.4 \%)$ & $2,690(20.7 \%)$ & $17,432(22.7 \%)$ \\
\hline 2 & $19,149(21.3 \%)$ & $2,757(21.2 \%)$ & $16,392(21.3 \%)$ \\
\hline 3 & $17,592(19.6 \%)$ & $2,510(19.3 \%)$ & $15,082(19.6 \%)$ \\
\hline 4 & $16,904(18.8 \%)$ & $2,560(19.7 \%)$ & $14,344(18.7 \%)$ \\
\hline 5 & $16,130(17.9 \%)$ & $2,495(19.2 \%)$ & $13,635(17.7 \%)$ \\
\hline \multicolumn{4}{|l|}{ Past medical history } \\
\hline Stroke & $3,094(3.4 \%)$ & $226(1.7 \%)$ & $2,868(3.7 \%)$ \\
\hline Acute myocardial infarction & $6,434(7.2 \%)$ & $817(6.3 \%)$ & $5,617(7.3 \%)$ \\
\hline Heart failure & $13,971(15.5 \%)$ & $1,280(9.8 \%)$ & $12,691(16.5 \%)$ \\
\hline COPD & $24,561(27.3 \%)$ & $2,917(22.4 \%)$ & $21,644(28.2 \%)$ \\
\hline Cancer & $18,946(21.1 \%)$ & $1,985(15.3 \%)$ & $16,961(22.1 \%)$ \\
\hline Hypertension & $69,606(77.4 \%)$ & $9,821(75.5 \%)$ & $59,785(77.8 \%)$ \\
\hline Diabetes & $27,066(30.1 \%)$ & $3,546(27.3 \%)$ & $23,520(30.6 \%)$ \\
\hline Dementia & $9,179(10.2 \%)$ & $428(3.3 \%)$ & $8,751(11.4 \%)$ \\
\hline Falls & $25,645(28.5 \%)$ & $2,951(22.7 \%)$ & $22,694(29.5 \%)$ \\
\hline Parkinson's disease & $2,574(2.9 \%)$ & $158(1.2 \%)$ & $2,416(3.1 \%)$ \\
\hline Hypotension & $3,214(3.6 \%)$ & $324(2.5 \%)$ & $2,890(3.8 \%)$ \\
\hline Renal failure & $2,793(3.1 \%)$ & $198(1.5 \%)$ & $2,595(3.4 \%)$ \\
\hline Fracture in the prior year & $1,430(1.6 \%)$ & $82(0.6 \%)$ & $1,348(1.8 \%)$ \\
\hline Glaucoma & $13,674(15.2 \%)$ & $11,663(15.2 \%)$ & $2,011(15.5 \%)$ \\
\hline \multicolumn{4}{|l|}{ Health care use } \\
\hline \multicolumn{4}{|c|}{ No. of admissions to hospital, prior 2 years } \\
\hline Mean $\pm S D$ & $1.3 \pm 1.9$ & $0.8 \pm 1.4$ & $1.4 \pm 2.0$ \\
\hline Median (IQR) & $1(0-2)$ & $0(0-1)$ & $1(0-2)$ \\
\hline \multicolumn{4}{|l|}{ ADG Score } \\
\hline Mean $\pm S D$ & $13.3 \pm 4.2$ & $12.4 \pm 4.1$ & $13.4 \pm 4.2$ \\
\hline Median (IQR) & $13(11-16)$ & $13(10-15)$ & $14(11-16)$ \\
\hline Has a family doctor & $70,121(78.0 \%)$ & $10,550(81.1 \%)$ & $59,571(77.5 \%)$ \\
\hline Cardiologist care in prior 2 years & $49,239(54.8 \%)$ & $7,153(55.0 \%)$ & $42,086(54.7 \%)$ \\
\hline Home care visit in last 3 months & $19,698(21.9 \%)$ & $1,124(8.6 \%)$ & $18,574(24.2 \%)$ \\
\hline \multicolumn{4}{|l|}{ ED visit } \\
\hline \multicolumn{4}{|l|}{ ED CTAS score } \\
\hline 1 or 2 & $8,602(9.6 \%)$ & $2,122(16.3 \%)$ & $6,480(8.4 \%)$ \\
\hline 3 & $48,338(53.8 \%)$ & $8,735(67.1 \%)$ & $39,603(51.5 \%)$ \\
\hline 4 or 5 & $32,957(36.7 \%)$ & $2,155(16.6 \%)$ & $30,802(40.1 \%)$ \\
\hline \multicolumn{4}{|l|}{ Hospital type } \\
\hline Small & $10,868(12.1 \%)$ & $1,014(7.8 \%)$ & $9,854(12.8 \%)$ \\
\hline Community & $65,283(72.6 \%)$ & $9,194(70.7 \%)$ & $56,089(73.0 \%)$ \\
\hline Teaching & $13,746(15.3 \%)$ & $2,804(21.5 \%)$ & $10,942(14.2 \%)$ \\
\hline Brought by ambulance & $22,648(25.2 \%)$ & $4,247(32.6 \%)$ & $18,401(23.9 \%)$ \\
\hline
\end{tabular}

the risk was low overall among all vertiginous patients $(0.6 \%)$. This provides some reassurance to managing emergency physicians; however, the addition of opioid analgesic medication substantially increased the risk, and falls that did not result in a fracture, as well as fractures seen in outpatient clinics and patients who didn't seek medical attention, were not captured in this rate. To provide context, we estimate that, if the risk of fracture with opioids increases by 3.59 on a baseline frequency of $\sim 0.6 \%$, the resulting frequency of $2.1 \%$ indicates a number needed to harm of 64 . We reason that performing a cursory check of the patient's medication list prior to discharge requires relatively little time investment on the part of the managing physician, which is justified in order to avoid even a small number of repeat ED visits for an injury that was substantial enough to cause a broken bone. 
Table 3. Baseline access to opioid analgesic medication and fractures post-ED visit, by cohort type

\begin{tabular}{|c|c|c|c|c|c|}
\hline Characteristic & $\begin{array}{c}\text { Total } \\
(N=89,897)\end{array}$ & $\begin{array}{l}\text { Vertigo cohort } \\
(n=13,012)\end{array}$ & $95 \% \mathrm{Cl}$ & $\begin{array}{l}\text { UTI cohort } \\
(n=76,885)\end{array}$ & $95 \% \mathrm{Cl}$ \\
\hline Opioid prescription & $20,645(23.0 \%)$ & $1,676(12.9 \%)$ & $12.3-13.5$ & $18,969(24.7 \%)$ & $24.4-25.0$ \\
\hline Fracture within 90 days of discharge & $1,043(1.2 \%)$ & $79(0.61 \%)$ & $4.7-7.4$ & $964(1.25 \%)$ & $1.2-1.3$ \\
\hline
\end{tabular}

\begin{tabular}{|c|c|c|c|c|}
\hline Variable & Parameter estimate & $H R$ & $95 \% \mathrm{Cl}$ & $p$-value* \\
\hline Vertigo & -0.55826 & 0.57 & $0.44-0.74$ & $<0.001$ \\
\hline Drug & 0.52059 & 1.68 & $1.43-1.97$ & $<0.001$ \\
\hline Vertigo*drug (interaction term) & 0.75686 & 2.13 & N/A & 0.01 \\
\hline Age & 0.04279 & 1.04 & $1.03-1.05$ & $<0.001$ \\
\hline Female & 0.64493 & 1.91 & $1.62-2.24$ & $<0.001$ \\
\hline \multicolumn{5}{|l|}{ Income quintile (reference $=$ income quintile 1 ) } \\
\hline Income quintile 2 & -0.21977 & 0.80 & $0.67-0.97$ & 0.02 \\
\hline Income quintile 3 & -0.02676 & 0.97 & $0.81-1.17$ & 0.77 \\
\hline Income quintile 4 & -0.02349 & 0.98 & $0.81-1.17$ & 0.80 \\
\hline Income quintile 5 & -0.09289 & 0.91 & $0.75-1.10$ & 0.34 \\
\hline ADG score & 0.00499 & 1.01 & $0.99-1.02$ & 0.61 \\
\hline Stroke & -0.00281 & 1.00 & $0.75-1.32$ & 0.98 \\
\hline Acute myocardial infarction & -0.14495 & 0.87 & $0.68-1.10$ & 0.24 \\
\hline Heart failure & 0.23841 & 1.27 & $1.09-1.48$ & 0.003 \\
\hline Cancer & 0.02519 & 1.03 & $0.88-1.19$ & 0.75 \\
\hline Hypertension & -0.06371 & 0.94 & $0.80-1.10$ & 0.44 \\
\hline Diabetes & -0.11009 & 0.90 & $0.78-1.03$ & 0.12 \\
\hline Dementia & 0.25102 & 1.29 & $1.09-1.52$ & 0.003 \\
\hline Falls & 0.50996 & 1.67 & $1.46-1.91$ & $<0.001$ \\
\hline Parkinson's disease & 0.41788 & 1.52 & $1.16-1.98$ & 0.002 \\
\hline Hypotension & 0.10811 & 1.11 & $0.85-1.46$ & 0.43 \\
\hline Renal failure & 0.01061 & 1.01 & $0.74-1.38$ & 0.95 \\
\hline Fracture in the prior year & 0.03835 & 1.04 & $0.75-1.43$ & 0.82 \\
\hline Glaucoma & 0.14534 & 1.16 & $0.99-1.36$ & 0.07 \\
\hline No. of admissions to hospital in prior 2 years & 0.04725 & 1.05 & $1.02-1.08$ & 0.004 \\
\hline Has family doctor & -0.00605 & 0.99 & $0.86-1.15$ & 0.94 \\
\hline Cardiologist care in prior 2 years & 0.04137 & 1.04 & $0.91-1.19$ & 0.54 \\
\hline Home care visit in the last 3 months & 0.40586 & 1.50 & $1.31-1.72$ & $<0.001$ \\
\hline \multicolumn{5}{|l|}{ ED CTAS score ( 1 = highest acuity) } \\
\hline 1 or 2 & 0.11362 & 1.12 & $0.91-1.38$ & 0.28 \\
\hline 4 or 5 & 0.08493 & 1.09 & $0.95-1.25$ & 0.24 \\
\hline \multicolumn{5}{|l|}{ Hospital type (reference = community) } \\
\hline Small & -0.12773 & 0.88 & $0.71-1.09$ & 0.24 \\
\hline Teaching & 0.08389 & 1.09 & $0.92-1.28$ & 0.32 \\
\hline Ambulance arrival & 0.16122 & 1.18 & $1.02-1.36$ & 0.03 \\
\hline
\end{tabular}

While previous studies have shown that elderly patients with dizziness are at an increased risk of falls, ${ }^{22,23}$ few studies have examined the risk of fractures specifically among discharged ED patients with peripheral vertigo. A Taiwanese population-based study showed a small increased risk of fracture (odds ratio [OR] 1.14, 95\% CI 1.04-1.25) among patients with benign positional peripheral vertigo compared to 
randomly selected controls, ${ }^{24}$ while our previous population-based work found no increased risk of falls, fractures, or other injuries among ED patients discharged with peripheral vertigo who were propensity score-matched to controls. ${ }^{7}$ The addition of a prescription opioid medication, however, has not previously been assessed, to the best of our knowledge.

Many patients with vertigo encounter some degree of handicap and/or restriction of activity as a result of their symptoms. These patients can have significant physical and psychological effects from the diagnosis, which include a fear of falling and problems with mobility and carrying out their daily routines. ${ }^{25}$ These may lead to loss of independence and inactivity, particularly in elderly patients; however, the inactivity and caution exercised with daily activities among these patients may also account for the lack of increased fall and fracture risk found in our previous study. ${ }^{7}$ The results of the current study suggest that the addition of an opioid analgesic prescription medication, with its attendant side-effect profile, overcomes the patient's ability to compensate.

\section{LIMITATIONS}

This study has several limitations. We calculated opioid analgesic use based on the prescription provided, which assumes that patients actually took the medication, and that it was taken consistently rather than intermittently. This likely results in some misclassification of opioid use, which would be expected to underestimate the real effect of current opioid use on the risk of fractures. The size of the administrative databases allows for assessment of low-frequency events, but databases may have coding inaccuracies; however, we validated the ICD-10 codes for peripheral vertigo and used previously validated algorithms for determining many comorbidities. We were only able to assess medication use in patients aged 65 and older, which limits the generalizability of our findings to an older patient population.

We were only able to capture fractures that resulted in an ED visit or hospitalization. As such, unattended fractures and those diagnosed in an outpatient clinic were not included, so that the total number of fractures is likely higher than our estimate. We purposely chose fractures instead of simply falls because the latter can lead to a range of injury severity, and our goal was to focus on significant injury. Finally, this study was retrospective, and while we adjusted for many comorbidities and included adjusted diagnostic group (ADG) scores in our model, without randomisation there may be residual differences between groups due to unmeasured confounders. The vertigo cohort had a lower hazard of fracture than the UTI cohort, suggesting that they either compensated for their perceived instability in a way that UTI patients did not or that they were healthier despite adjustment for known confounders. The latter would likely lead to a conservative bias, where the true difference between cohorts in the effect of opioid analgesic medication is likely even larger (i.e., if the vertigo patients were healthier, they would be less likely to be injured than sicker UTI patients). A randomised trial would overcome these potential differences; however, given the number of outcomes and the sample size required to power such a study, we may be limited to a retrospective design. Lending face validity to our model, expected predictors were associated with falls, including older age, history of falls, dementia, Parkinson's disease, and home care visits.

\section{CONCLUSIONS}

In this population-based study, patients discharged from the ED with a diagnosis of a peripheral vertigo syndrome who had access to a previously prescribed opioid analgesic medication had a risk of bone fracture that was more than three times that of those who did not fill such a prescription. The effect was much greater in these patients compared to patients discharged with a diagnosis of a UTI. Physicians who discharge these patients should briefly review the medication profile and consider alternatives for opioids where possible, and all physicians should be cautious in offering new opioid prescriptions to this patient population.

Acknowledgements: Dr. Atzema was supported by a New Investigator Award from the Heart and Stroke Foundation of Ontario (HSFO). Drs. Austin and Kapral were supported by Career Investigator Awards from the HSFO. This study was supported by the Institute for Clinical Evaluative Sciences, which is funded by an annual grant from the Ontario Ministry of Health and Long-Term Care (MOHLTC). The opinions, results, and conclusions reported in this paper are those of the authors and are independent from the funding sources. No endorsement by the ICES or the Ontario MOHLTC is intended or should be inferred. Parts of this material are based on data and/or information compiled and provided by CIHI. However, the analyses, conclusions, opinions, and statements expressed in 
the material are those of the author(s) and not necessarily those of CIHI.

Competing interests: None to declare.

\section{SUPPLEMENTARY MATERIALS}

For supplementary material/s referred to in this article, please visit https://doi.org/10.1017/cem.2017.37

\section{REFERENCES}

1. Kerber KA, Meurer WJ, West BT, Fendrick AM. Dizziness presentations in U.S. emergency departments, 1995-2004. Acad Emerg Med 2008;15(8):744-50.

2. Walker HK, Hall WD, Jurst JW. Clinical Methods: The History, Physical, and Laboratory Examinations. 3rd ed. Boston: Butterworth; 1990.

3. Cappello M, di Blasi U, di Piazza L, et al. Dizziness and vertigo in a department of emergency medicine. Eur 7 Emerg Med 1995;2(4):201-11.

4. Karatas M. Central vertigo and dizziness: epidemiology, differential diagnosis, and common causes. Neurologist 2008;14(6):355-64.

5. Kerber KA, Baloh RW. The evaluation of a patient with dizziness. Neurol Clin Pract 2011;1(1):24-33.

6. Holmes S, Padgham ND. A review of the burden of vertigo. 7 Clin Nurs 2011;20(19-20):2690-701.

7. Atzema CL, Grewal K, Lu H, et al. Outcomes among patients discharged from the emergency department with a diagnosis of peripheral vertigo. Ann Neurol 2016;79(1):32-41.

8. International Opioids Control Board. Opioid Consumption Motion Chart. Madison: Board of Regents of the University of Wisconsin System; 2012. Available at: https://ppsg.medicine. wisc.edu/chart (accessed May 18, 2017).

9. Gomes T, Mamdani MM, Paterson JM, Dhalla IA, Juurlink DN. Trends in high-dose opioid prescribing in Canada. Can Fam Physician 2014;60(9):826-32.

10. Rolita L, Spegman A, Tang X, Cronstein BN. Greater number of opioid analgesic prescriptions for osteoarthritis is associated with falls and fractures in elderly adults. $7 \mathrm{Am}$ Geriatr Soc 2013;61(3):335-40.

11. Grewal K, Austin PC, Kapral MK, Lu H, Atzema CL. Missed stroked using computed tomography imaging in patients with vertigo: a population-based cohort study. Stroke 2015;46(1):108-13.

12. Ontario Ministry of Health and Long-Term Care. Ontario Health Insurance Plan (OHIP). Available at: http://www. health.gov.on.ca/en/public/programs/ohip/(accessed May 18, 2017).
13. Iron K, Zagorski BM, Sykora K, Manuel DG. Living and Dying in Ontario: An Opportunity for Improved Health Information. Toronto: Institute for Clinical Evaluative Sciences; 2008. Available at: https://www.healthsystemsevidence.org/articles/ 26617-living-and-dying-in-ontario-an-opportunity-forimproved-health-information-ontario? $\mathrm{t}=$ Livingandd\&amp source $=$ search\&amplang $=$ pt (accessed May 18, 2017).

14. Austin PC, Daly PA, Tu JV. A multicenter study of the coding accuracy of hospital discharge administrative data for patients admitted to cardiac care units in Ontario. Am Heart 7 2002;144(2):290-6.

15. Gershon AS, Wang C, Guan J, et al. Identifying individuals with physician diagnosed COPD in health administrative databases. COPD 2009;6(5):388-94.

16. Hux JE, Ivis F, Flintoft V, Bica A. Diabetes in Ontario: determination of prevalence and incidence using a validated administrative data algorithm. Diabetes Care 2002;25(3):512-6.

17. Schultz SE, Rothwell DM, Chen Z, Tu K. Identifying cases of congestive heart failure from administrative data: a validation study using primary care patient records. Chronic Dis Inj Can 2013;33(3):160-6.

18. Tu K, Campbell NR, Chen ZL, Cauch-Dudek KJ, McAlister FA. Accuracy of administrative databases in identifying patients with hypertension. Open Med 2007;1(1):e18-e26.

19. Charlson ME, Pompei P, Ales KL, MacKenzie CR. A new method of classifying prognostic comorbidity in longitudinal studies: development and validation. 7 Chronic Dis 1987; 40(5):373-83.

20. Johns Hopkins University. The Fohns Hopkins ACG ${ }^{\circledR}$ System: Decades of Impact on Population Health Research and Practice. Baltimore: Johns Hopkins University; 2017. Available at: http://www.acg.jhsph.edu (accessed May 19, 2017).

21. Beveridge R, Clarke B, Janes L, et al. Implementation Guidelines for the Canadian Emergency Department Triage \& Acuity Scale (CTAS). Ottawa: Canadian Association of Emergency Physicians; 2015. Available at: http://caep.ca/sites/caep.ca/ files/caep/files/ctased16.pdf (accessed May 19, 2017).

22. Fernandez L, Breinbauer HA, Delano PH. Vertigo and dizziness in the elderly. Front Neurol 2015;6:144.

23. Agrawal Y, Carey JP, Della Santina CC, Schubert MC, Minor LB. Disorders of balance and vestibular function in US adults: data from the National Health and Nutrition Examination Survey, 2001-2004. Arch Intern Med 2009; 169(10):938-44.

24. Liao WL, Chang TP, Chen HJ, Kao CH. Benign paroxysmal positional vertigo is associated with an increased risk of fracture: a population-based cohort study. 7 Orthop Sports Phys Therapy 2015;45(5):406-12.

25. Mueller M, Schuster E, Strobl R, Grill E. Identification of aspects of functioning, disability and health relevant to patients experiencing vertigo: a qualitative study using the international classification of functioning, disability and health. Health Qual Life Outcomes 2012;10:75. 